\title{
Multifamily Envelope Leakage Model
}

O. Faakye and D. Griffiths

Consortium for Advanced Residential Buildings 


\section{NOTICE}

This report was prepared as an account of work sponsored by an agency of the United States government. Neither the United States government nor any agency thereof, nor any of their employees, subcontractors, or affiliated partners makes any warranty, express or implied, or assumes any legal liability or responsibility for the accuracy, completeness, or usefulness of any information, apparatus, product, or process disclosed, or represents that its use would not infringe privately owned rights. Reference herein to any specific commercial product, process, or service by trade name, trademark, manufacturer, or otherwise does not necessarily constitute or imply its endorsement, recommendation, or favoring by the United States government or any agency thereof. The views and opinions of authors expressed herein do not necessarily state or reflect those of the United States government or any agency thereof.

Available electronically at http://www.osti.gov/bridge

Available for a processing fee to U.S. Department of Energy and its contractors, in paper, from:

U.S. Department of Energy

Office of Scientific and Technical Information

P.O. Box 62

Oak Ridge, TN 37831-0062

phone: 865.576 .8401

fax: 865.576.5728

email: mailto:reports@adonis.osti.gov

Available for sale to the public, in paper, from:

U.S. Department of Commerce

National Technical Information Service

5285 Port Royal Road

Springfield, VA 22161

phone: 800.553 .6847

fax: 703.605.6900

email: orders@ntis.fedworld.gov

online ordering: http://www.ntis.gov/ordering.htm 


\title{
Multifamily Envelope Leakage Model
}

\author{
Prepared for:
}

The National Renewable Energy Laboratory

On behalf of the U.S. Department of Energy's Building America Program

Office of Energy Efficiency and Renewable Energy

15013 Denver West Parkway

Golden, CO 80401

NREL Contract No. DE-AC36-08GO28308

Prepared by:

Omari Faakye and Dianne Griffiths

Steven Winter Associates, Inc.

of the

Consortium for Advanced Residential Buildings (CARB)

61 Washington Street

Norwalk, CT 06854

NREL Technical Monitor: Cheryn Metzger

Prepared under Subcontract No. KNDJ-0-40342-04

May 2015 
The work presented in this report does not represent performance of any product relative to regulated minimum efficiency requirements.

The laboratory and/or field sites used for this work are not certified rating test facilities. The conditions and methods under which products were characterized for this work differ from standard rating conditions, as described.

Because the methods and conditions differ, the reported results are not comparable to rated product performance and should only be used to estimate performance under the measured conditions. 


\section{Contents}

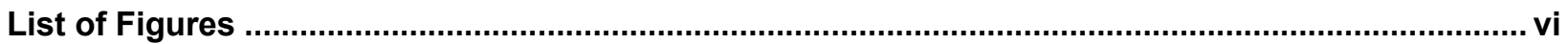

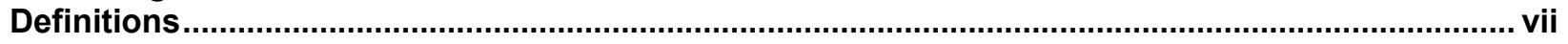

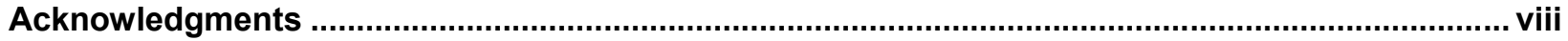

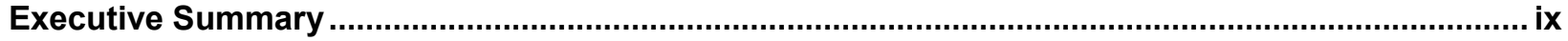

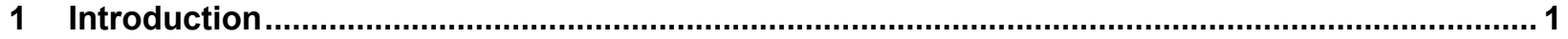

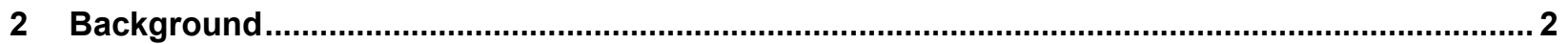

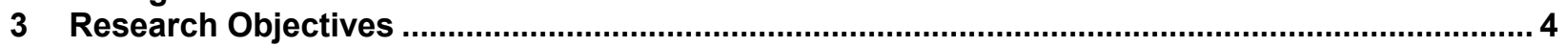

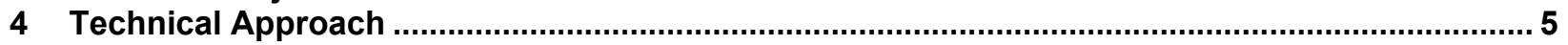

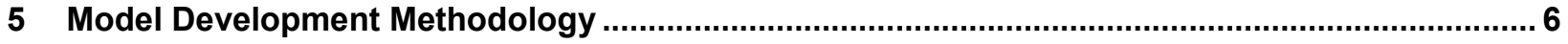

5.1 Theoretical Development of a Multilinear Regression Analysis .................................................. 6

5.2 Building and Unit Features Considered .................................................................................. 7

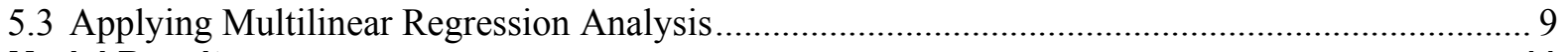

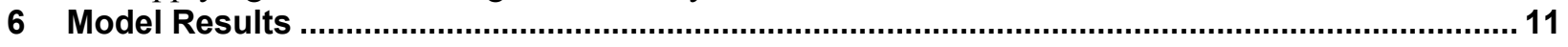

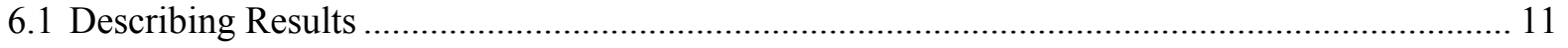

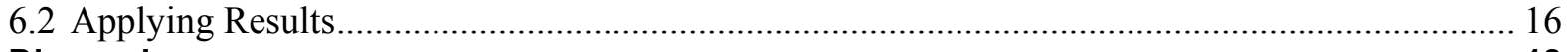

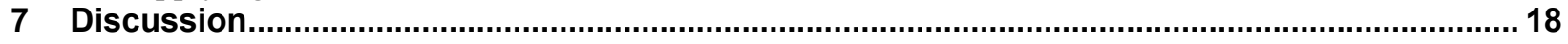

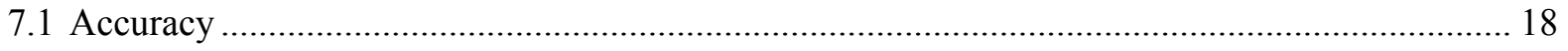

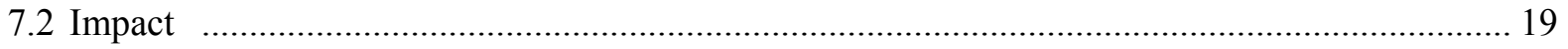

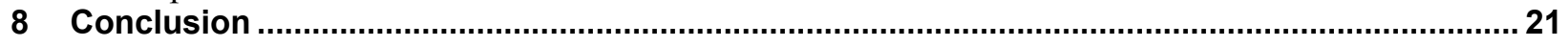

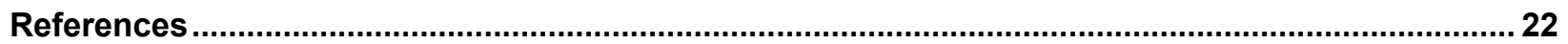




\section{List of Figures}

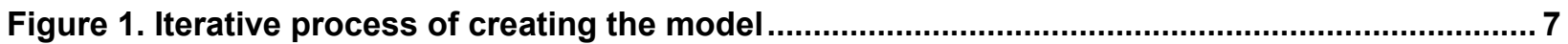

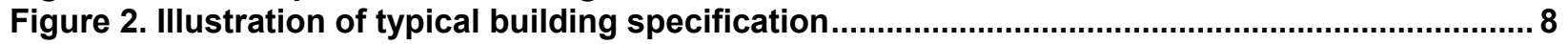

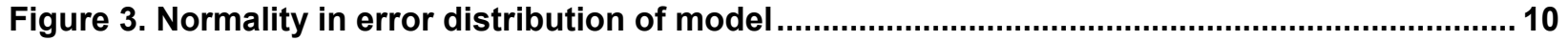

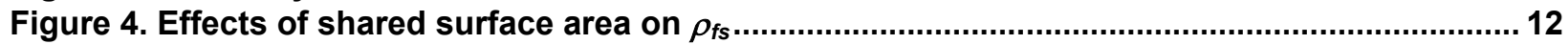

Figure 5. Adjusted plots for predictors in model....................................................................... 15

Figure 6. Predicted FGT value against ST value using the model.................................................... 16

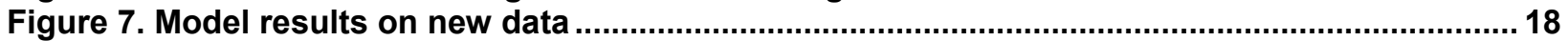

Figure 8. Distribution of measured guarded values ............................................................................ 19

Unless otherwise noted, all figures were created by CARB.

\section{List of Tables}

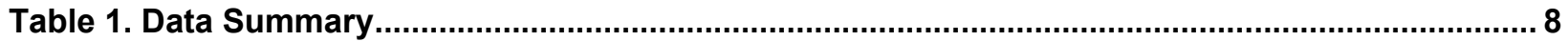

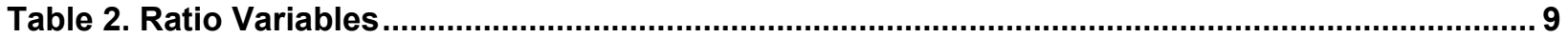

Table 3. Coding Scheme for Categorical Variables .................................................................. 9

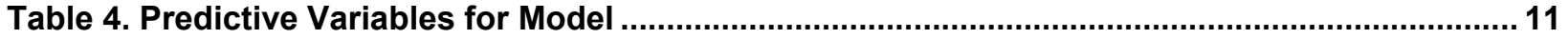

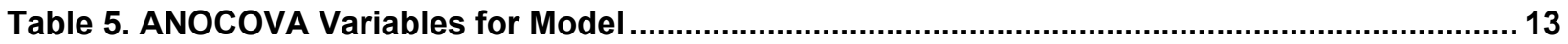

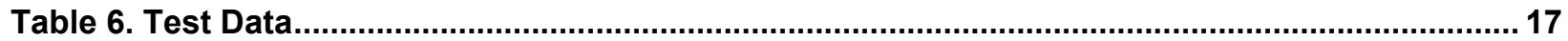

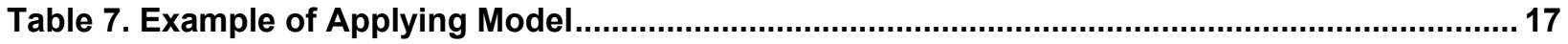

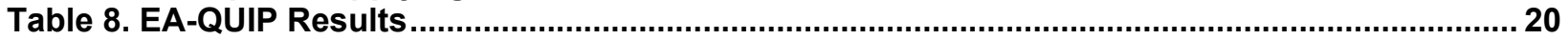

Unless otherwise noted, all tables were created by CARB. 


\section{Definitions}

$\begin{array}{ll}\text { ANOCOVA } & \text { Analysis of Covariance } \\ \text { CARB } & \text { Consortium for Advanced Residential Buildings } \\ \text { CFM } & \text { Cubic Feet per Minute } \\ \text { EA-QUIP } & \text { Energy Audit using the Queens Information Package } \\ \text { FGT } & \text { Fully guarded test } \\ \text { LBNL } & \text { Lawrence Berkeley National Laboratory } \\ \text { MLR } & \text { Multilinear Regression } \\ \text { Pa } & \text { Pascal } \\ \text { RMSE } & \text { Root Mean Square Error } \\ \text { SIR } & \text { Saving to Investment Ratio } \\ \text { ST } & \text { Solo Test }\end{array}$




\section{Acknowledgments}

The Consortium for Advanced Residential Buildings would like to thank those who have enthusiastically supported this effort. A special thanks for the input of project advisors Michael Lubliner, Terry Brennan, Gary Nelson, Collin Olson, and Iain Walker. We are also grateful to those that contributed test data to our database, including Anthony Cox and Chase Counts of the National Council of Research and Training, David Bohac of Center for Energy Environment, Eyu-Jin Kim of Southface Institute, John Dentz of Levy Partnership, and Matthew Root of Conservation Services Group. 


\section{Executive Summary}

"The cost for blower testing is high, because it is labor intensive, and it may disrupt occupants in multiple units. This high cost and disruption deter program participants, and dissuade them from pursuing energy improvements that would trigger air leakage testing, such as improvements to the building envelope."

This statement found in a 2012 report by Heschong Mahone Group for several California interests emphasizes the importance of reducing the cost and complexity of blower testing in multifamily buildings. Energy efficiency opportunities are being bypassed.

The cost of single blower testing is on the order of $\$ 300$. The cost for guarded blower door testing - the more appropriate test for assessing energy savings opportunities - could easily be six times that, and that's only if you have the equipment and simultaneous access to multiple apartments. Thus, the proper test is simply not performed. This research seeks to provide an algorithm for predicting the guarded blower door test result based upon a single, total blower door test.

Standards and protocols for conducting blower door testing to measure the envelope leakage of single-family, detached homes are well understood and consistently applied. It's safe to assume that all envelope leakage is to the outside and is thus an energy penalty. This is not the case for multifamily and single-family attached housing. For these types of housing, a distinction between total leakage and leakage to the outside is appropriate.

In 2012, the Consortium for Advanced Residential Buildings examined a limited amount of test data to assess the viability of developing an empirical model for estimating outside air leakage based upon a measurement of total leakage and a few key characteristics of the multifamily dwelling unit. Using blower door test data available from four multifamily projects, the framework for a simple algorithm to predict leakage to outside was outlined. While the dataset was very limited, preliminary analyses suggested that statistically significant predictors are present and can support the development of an algorithm.

The objective of the 2013 research project was to develop the model for predicting fully guarded test results, using unguarded test data and specific building features of apartment units. The data used was composed of 236 observations from four different climate zones, 17 multifamily buildings, and 35 possible predictor variables.

Considering the importance of ease of use, the most practical model was the multilinear regression model. A stepwise regression analysis identified six variables as significant given the data available: climate zone, ductwork location, door area, shared surface area, envelope perimeter, and age. The adjusted coefficient of determination $\mathrm{R}^{2}$ value of the model was 0.53 with a root mean square error of 0.13 . When tested against data that were not included in the development of the model, prediction accuracy was within $19.6 \%$. And, with only six easily obtained predictors, the model will be relatively easy to apply. 


\section{Introduction}

Standards and protocols for conducting blower door testing to measure the envelope leakage of single-family, detached homes are well understood and consistently applied. It's safe to assume that all envelope leakage is to the outside and is thus an energy penalty. This is not the case for multifamily and single-family, attached housing. For these types of housing, a distinction between total leakage and leakage to the outside is appropriate.

Measuring and minimizing total leakage are encouraged for energy and for indoor air quality concerns. However, if total leakage is assumed to be all to the outside in energy models, the energy benefits of air sealing can be significantly overpredicted. Some practitioners and program administrators prefer fully guarded tests (FGTs). This test method requires all neighboring units to be pressurized or depressurized at the same time and to the same pressure as the unit being tested to eliminate any transfer of air between units and isolate only the leakage that is escaping to the outdoors. Performing guarded blower door testing is by far more expensive, time consuming, and intrusive to occupants than testing an individual unit. What is needed is a simpler, less costly method to arrive at the leakage to the outside based on unguarded total leakage or solo test (ST) results. This research seeks to create a model that can reasonably predict the FGT results given the ST results from the field for various building types. All field test values were obtained at $50 \mathrm{~Pa}$ and assumed to be obtained by depressurization. 


\section{Background}

Much work has been done on blower door-based test methods for measuring air leakage. In 1987, the Canadian R-2000 program evaluated four different ways of blower door testing units within a six-unit rowhome building. These methods were the (1) detached-unit method (demising walls treated as exterior for conservative estimate of infiltration); (2) pressure equalization method (guarded blower door testing to negate airflow between adjoining units); (3) pressure drop method (measure pressure in adjoining units to determine level of connectivity); and (4) whole-building method (test all adjoined unit simultaneously and use a weighted average to determine infiltration of each unit) (Sheltair1987).

In a similar effort in 1995, Steven Winter Associates, Inc. and Lawrence Berkeley National Laboratory (LBNL) conducted research focused on the applicability of two-blower door and single-blower door multizone pressurization techniques for estimating the air leakage characteristics of New York State multifamily apartment buildings. Results from this research demonstrated that a multizone single-door test was able to achieve results within $25 \%$ of the leakage area of a two-door technique (NYSERDA 1995).

In addition to these research efforts, several articles in the last few years have provided recommendations for testing attached dwellings. A 2007 Home Energy article entitled "Measuring Leakage in High-Rise Buildings" by Colin Genge outlined an approach for multifamily guarded blower door testing, which aims to account for interzone leakage. Still, applying this technique can require a large number of blower doors and personnel and access to all apartments bordering the unit being tested.

Another Home Energy article, "Blower Door Testing in Multifamily Buildings" (Hynek 2011), focused on measuring an entire building rather than individual apartment units. Though effective, the coordination required and expense of time and personnel related with this test method make it inappropriate for mass implementation.

In 2012, the Heschong Mahone Group published a report on a project funded by several California interests to "identify and hopefully reduce barriers to multi-family energy upgrade program implementation and participation by framing the issues surrounding air leakage, and proposing protocols to conduct air leakage testing for multi-family buildings, in anticipation of a statewide rollout of a whole-building, multi-family energy upgrade program" (HMG 2012). The potential value of the Consortium for Advanced Residential Buildings (CARB) research effort is cited in this report.

Laboratory research addressing leakage between attached units is also being conducted. Researchers at LBNL are researching measurement methods for determining interzone leakages and their uncertainty (Hult 2012). While this work has different objectives, it could be relevant because LBNL researchers are also requesting available multifamily blower door test data from the building science industry.

Because of the costs and complexity of implementing many of the test methods described above, CARB conducted a research project in 2012 that examined a limited amount of test data to assess 
the viability of developing an empirical model for estimating outside air leakage based upon a measurement of total leakage and a few key characteristics of the dwelling unit. Using blower door test data available from four multifamily projects, the framework for a simple algorithm to predict leakage to outside was outlined. While the dataset was very limited, preliminary analyses suggested that statistically significant predictors are present and can support the development of an algorithm. 


\section{Research Objectives}

This research project sought to build upon last year's work by creating a substantial database of blower door test and unit characteristic data and developing a more broadly applicable algorithm. The following research questions are addressed by this research:

- Can an empirical model based on a single blower door test and easily accessible data be developed for predicting thermal envelope leakage in multifamily buildings across the United States?

- Can this model be applied with reasonable accuracy across various types of buildings and across different climate regions? 


\section{Technical Approach}

The technical approach involved the following primary tasks:

1. Collect data. A "call for data" was distributed electronically within a Building America Update. CARB also directly contacted researchers in the building science community, including Center for Energy and Environment, Conservation Services Group, Heschong Mahone Group, and Southface Institute. The following information was requested:

i. Blower door test results, both guarded and unguarded, for the same dwelling unit

ii. Dwelling unit characteristics including location within the building, floor area, window area, heating, ventilation, and air conditioning type

iii. Building characteristics including location, age, and insulation levels

2. Data analysis and model development. Data received were organized into a database and statistically analyzed.

3. Testing of the model's accuracy. A subset of the data received was set aside and not included in the model development process. This subset was used to test the predictive ability of the model.

Throughout the project, a technical advisory panel reviewed and guided this research. Also, a technical paper on this work was presented at the ASHRAE 2014 Winter Meeting. The Residential Energy Services Network Multifamily Working Group has been following this work as well. 


\section{Model Development Methodology}

\subsection{Theoretical Development of a Multilinear Regression Analysis}

For the sake of having a concise model, a stepwise regression analysis was used to select the most significant set of predictors for the model. The stepwise method is essentially a forward selection procedure with the added condition that a variable already selected for the model can be deleted as in the backward selection procedure.

The stepwise regression method is an iterative process. Starting with an initial model; e.g., a constant, the F-test was used to investigate the significance of the model by adding or subtracting a variable. For more information on the F-test see Chatterjee and Price (1938). At each step of this iterative process, the p-value of an F-statistic is computed to test the explanatory power of models with or without a potential variable. If a variable is not in the model, the null hypothesis is that the variable would be zero if added to the model. If there is sufficient evidence to reject the null hypothesis, the variable is added to the model. In this research, the variable in the model with the lowest $p$-value less than an entrance tolerance of 0.05 was used. Conversely, if a variable is currently in the model, the null hypothesis is that the variable has a zero coefficient. If there is insufficient evidence to reject the null hypothesis, that is if the p-value, calculated from the F-statistic, is less than an exit tolerance of 0.10 , the variable is removed from the model (MathWorks 2013). Figure 1 illustrates the iterative process in a flow chart. For more information on performing the F-statistic and calculating p-values, see DeGroot and Schervish (1989). When all the variables in the model have been tested and are significant according to the tolerances mentioned above, the final model is then created with the remaining variables.

Stepwise regression could fail as a variable selection device because it is unrelated to theoretical considerations (Lewis-Beck 1978) and there is no guarantee that a different initial model or a different sequence of steps will not lead to a better fit. In this sense, stepwise models are locally optimal, but may not be globally optimal (MATLAB 2013). Next, the stepwise regression method is applied to the data while employing techniques to maximize its utility and reduce possible error in the model creating process. 


\section{Simplified Stepwise Method}

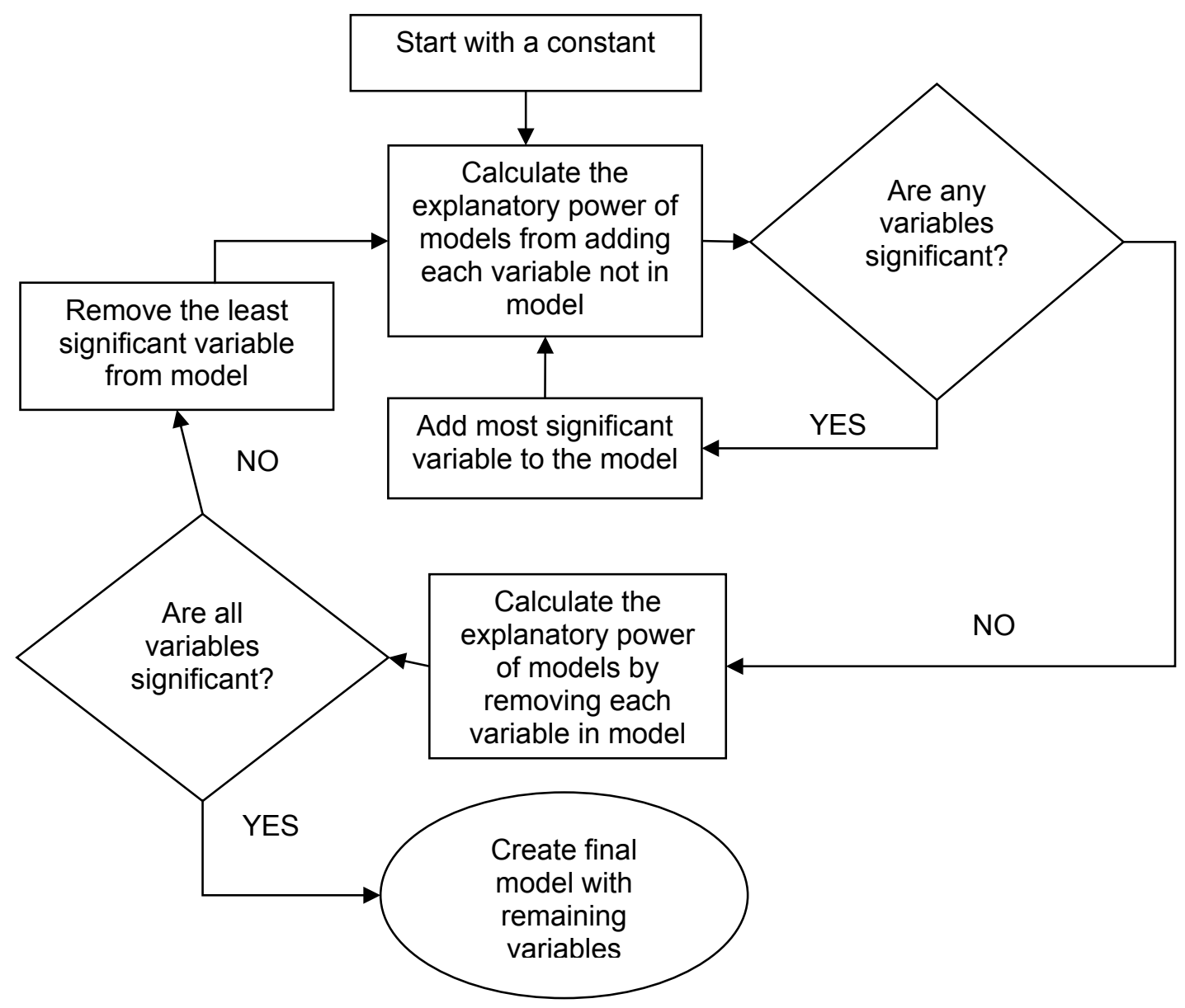

Figure 1. Iterative process of creating the model

\subsection{Building and Unit Features Considered}

In order to get a holistic sample of variables, both quantitative and qualitative predictors were selected. Variables were selected based on prior studies (Sherman 2007; NREL 2001a; NREL 2001b; Lukachko et al. 2013). Several ratios were calculated between the predictive variables. Quantitative variables considered were footprint area, window area, wall area, door area, shared wall area, shared surfaces area, exposed wall area, exposed surfaces area, unit height, number of floors, and age. Qualitative (categorical) variables considered were unit story level, unit location (end or interior), foundation type, construction material, building framing type, wall insulation, roof insulation, window type, window frame material, siding, common wall construction, space conditioning distribution system (ducted or unducted), and ductwork location. Figure 2 illustrates some of the variables considered for the model. 


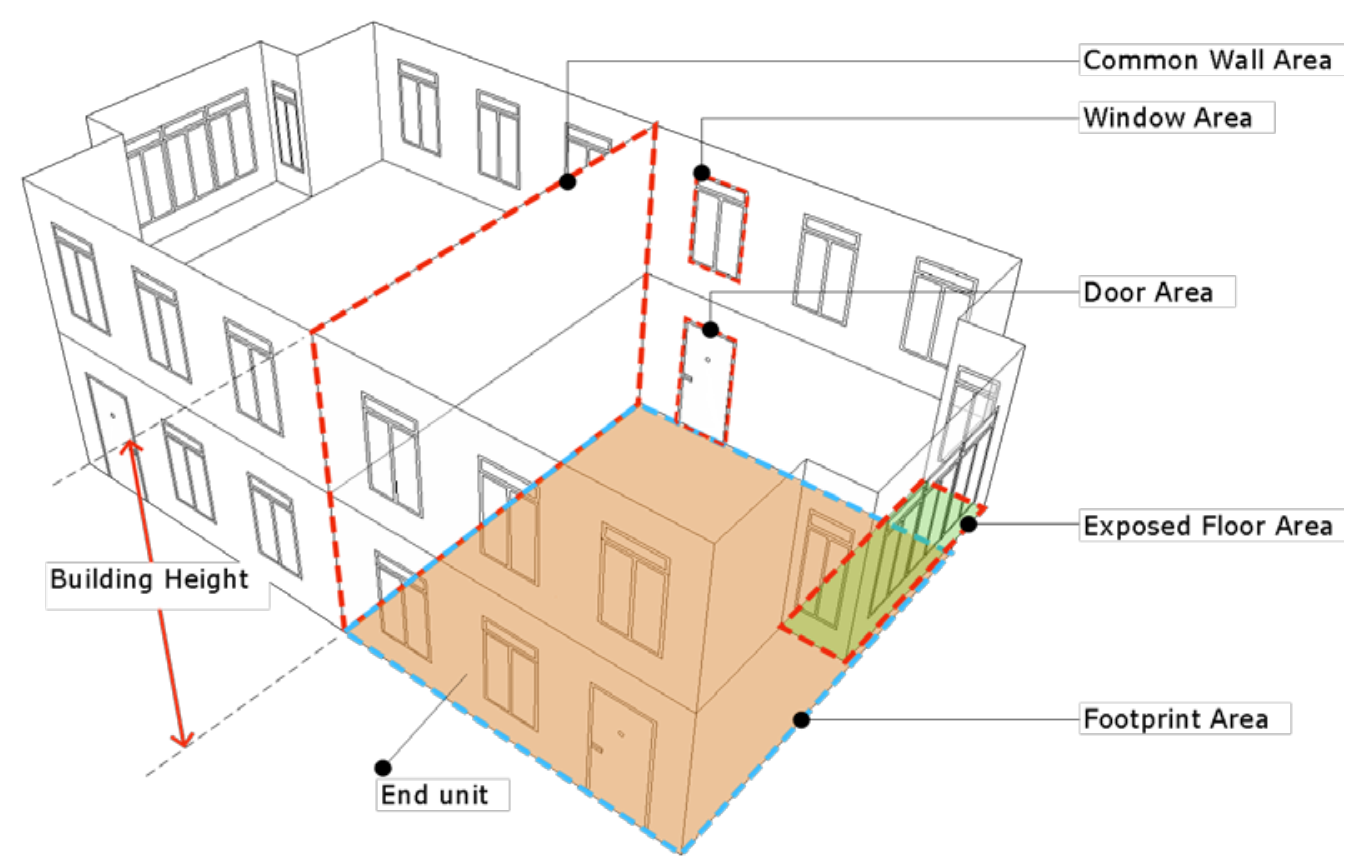

Figure 2. Illustration of typical building specification

Table 1 shows a summary of the data collected. A total of 236 units were obtained from 17 buildings. The buildings were located in a total of four International Energy Conservation Code climate zones. Most of the units were from low-rise multifamily buildings (maximum of three stories) with the exception of 14 units that were from a high-rise multifamily building of 11 stories. There were two main unit types, apartment and townhome.

Table 1. Data Summary

\begin{tabular}{c|c}
\hline Category & Value/Range \\
\hline Number of Buildings & 17 Buildings \\
\hline Number of Units & 236 Units \\
Climate Zones & $3 \mathrm{~A}, 4 \mathrm{~A}, 5 \mathrm{~A}, 6 \mathrm{~A}$ \\
Number of Stories & 2 and 3 \\
\hline Apartment Types & Apartment or Townhouse \\
\hline
\end{tabular}

To improve the strength and accuracy of the model, ratios were calculated between variables to create more interactions in addition to the additive interaction facilitated in multilinear regression (MLR) models. The ratios created are listed in Table 2.

For every categorical variable used, a set of dummy variables was created to describe each level in the variable by using a dummy coding scheme (UCLA 2013). This coding scheme assigns a value of 1 or 0 to the dummy variable by comparing each level of the categorical variable to a fixed reference level. Table 3 shows an example of dummy variables and corresponding values created for ductwork location. 
Table 2. Ratio Variables

\begin{tabular}{c|c}
\hline Ratio Variables & Description \\
\hline RCWTSA & Ratio of common wall to total surface area \\
RCWVSA & Ratio of common wall to vertical surface area \\
RSSATSA & Ratio of shared surface area to total surface area \\
RESATSA & Ratio of exposed surface area to total surface area \\
RWATEA & Ratio of window area to total exposed surface area \\
\hline RCWEP & Ratio of common wall to envelope perimeter \\
\hline RVSATEA & Ratio of vertical surface area to total exposed surface area \\
\hline RVSATSA & Ratio of vertical surface area to total surface area \\
\hline RNEPEP & Ratio of number of envelope panels/sides to envelope perimeter \\
\hline
\end{tabular}

Table 3. Coding Scheme for Categorical Variables

\begin{tabular}{c|c|c|c}
\hline $\begin{array}{c}\text { Dummy } \\
\text { Variable } \\
\text { Number }\end{array}$ & $\begin{array}{c}\text { Dummy Variables for } \\
\text { Duct Location }\end{array}$ & $\begin{array}{c}\text { Dummy Variable 2 in } \\
\text { Reference to Variable 1 }\end{array}$ & $\begin{array}{c}\text { Dummy Variable 3 in } \\
\text { Reference to Variable 1 }\end{array}$ \\
\hline $\mathbf{1}$ & $\begin{array}{c}\text { Ductwork location - } \\
\text { none }\end{array}$ & 0 & 0 \\
\hline $\mathbf{2}$ & $\begin{array}{c}\text { Ductwork location - } \\
\text { conditioned space } \\
\text { Ductwork location - } \\
\text { unconditioned space }\end{array}$ & 1 & 0 \\
\hline $\mathbf{3}$ & 0 & 1 \\
\hline
\end{tabular}

The fixed level in the dummy variable for DuctLocation ${ }^{2}$ is "None" (Dummy Variable 1). This is the case where a unit has no ducts. The reference point is seen as the point when all dummy variables are set to zero. As such, dummy variable Ductwork Location - None is represented when the two other duct location levels are set to zero. There were no units with ducts located in both conditioned and unconditioned space within the data analyzed. If there were such units, another level in the dummy variable would have been created.

The output of the model was chosen to be a ratio of FGT to ST values $\left(\rho_{f s}\right)$. The idea behind using this ratio was to have an output from the model that would easily describe how much of the total leakage from ST is air leakage to the outside from the FGT.

\subsection{Applying Multilinear Regression Analysis}

To justify the use of an MLR model, errors of the model have to be normally distributed. As expected, Figure 3 shows a normal curve superimposed over a histogram of the model's standardized errors and the errors are nearly normally distributed. In addition, according to the Kolmogorov-Smirnov test (Massey 1951), which compares the values in a data set to a standard normal distribution, the hypothesis that the response (fully guarded to ST values, $\rho_{\mathrm{fs}}$ ) is normally distributed, is not rejected at the 5\% significance level. Also, the standardized residuals

\footnotetext{
${ }^{1}$ Envelope Perimeter is the sum of the length of all the edges of an apartment unit envelope

${ }^{2}$ Variable names are written with each word capitalized
} 
of the final predictor variables were normally distributed with a constant covariance, confirming the assumed linear relation between predictors and the response. To minimize the expected prediction error from data splitting (Roecker 1991), 60\% of the data were taken as the training data for the model. The rest of the data were later used to test the model. The probability of arriving at a locally optimal model was reduced by creating several models from different sets of training data samples from the same data pool.

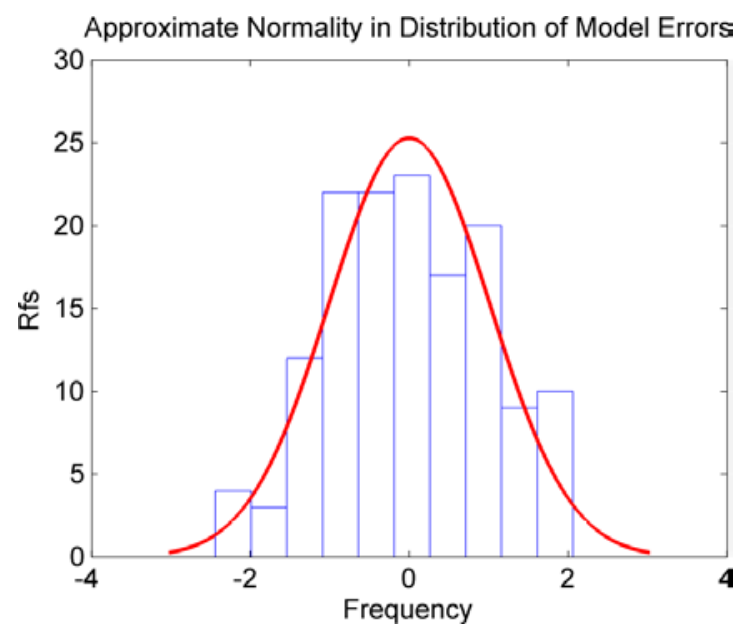

Figure 3. Normality in error distribution of model 


\section{Model Results}

\subsection{Describing Results}

Table 4 shows the results of the selected predictors for the model, their coefficients, and corresponding p-values from the t-test. For more information on the t-test see Chatterjee and Price (1938). With the exception of dummy variables ClimateZone_5a $\left(X_{1,2}\right)$, ClimateZone_6a $\left(X_{1,3}\right)$ and DuctworkLocation_conditioned $\left(X_{2,1}\right)$, all the p-values are less than 0.05 indicating the coefficients of the respective predictor variables are significant. Even though the individual coefficients of three dummy variables are insignificant, it will be shown later in an analysis of covariance (ANOCOVA) that the entire set of predictor variables taken collectively explain a significant part of the variation in the dependent variable $\rho_{f s}$. The coefficients of each variable signify the incremental value in $\rho_{f s}$ for a unit increase in predictor variables.

Table 4. Predictive Variables for Model

\begin{tabular}{c|c|c|c|c}
\hline \multicolumn{2}{c|}{ Predictor Variables (X) } & \multicolumn{2}{c|}{ Coefficients $(\boldsymbol{\alpha})$} & $\begin{array}{c}\text { p- } \\
\text { Values }\end{array}$ \\
\hline $\boldsymbol{X}_{\boldsymbol{0}}$ & Intercept & $\alpha_{0}$ & $8.61 \mathrm{E}-01$ & $1.54 \mathrm{E}-22$ \\
$\boldsymbol{X}_{1,1}$ & ClimateZone_4a & $\alpha_{1,1}$ & $-2.50 \mathrm{E}-01$ & $4.14 \mathrm{E}-06$ \\
$\boldsymbol{X}_{1,2}$ & ClimateZone_5a & $\alpha_{1,2}$ & $-4.23 \mathrm{E}-02$ & $5.08 \mathrm{E}-01$ \\
\hline $\boldsymbol{X}_{1,3}$ & ClimateZone_6a & $\alpha_{1,3}$ & $-1.10 \mathrm{E}-01$ & $5.66 \mathrm{E}-02$ \\
$\boldsymbol{X}_{2,1}$ & DuctworkLocation_conditioned space & $\alpha_{2,1}$ & $5.11 \mathrm{E}-02$ & $2.75 \mathrm{E}-01$ \\
$\boldsymbol{X}_{2,2}$ & DuctworkLocation_unconditioned space & $\alpha_{2,2}$ & $2.70 \mathrm{E}-01$ & $2.25 \mathrm{E}-16$ \\
$\boldsymbol{X}_{3}$ & DoorArea $\left(\mathrm{ft}^{2}\right)$ & $\alpha_{3}$ & $-4.43 \mathrm{E}-03$ & $3.61 \mathrm{E}-07$ \\
$\boldsymbol{X}_{4}$ & SharedSurfaceArea $\left(\mathrm{ft}^{2}\right)$ & $\alpha_{4}$ & $-1.59 \mathrm{E}-04$ & $1.69 \mathrm{E}-06$ \\
$\boldsymbol{X}_{5}$ & EnvelopePerimeter ${ }^{3}(\mathrm{ft})$ & $\alpha_{5}$ & $1.23 \mathrm{E}-03$ & $3.03 \mathrm{E}-06$ \\
$\boldsymbol{X}_{6}$ & Age (years) & $\alpha_{6}$ & $-5.39 \mathrm{E}-03$ & $2.62 \mathrm{E}-08$ \\
\hline
\end{tabular}

Equation 1 shows a simplified version of the model where $X_{i}$ terms are the predictor variable and $\alpha_{i}$ terms are the coefficients.

$$
\begin{gathered}
\rho_{f s}=\alpha_{0}+\alpha_{1,1} X_{1,1}+\alpha_{1,2} X_{1,2}+\alpha_{1,3} X_{1,3}+\alpha_{2,1} X_{2,1}+\alpha_{2,2} X_{2,2} \\
+\alpha_{3} X_{3}+\alpha_{4} X_{4}+\alpha_{5} X_{5}+\alpha_{6} X_{6}=\frac{\phi}{\sigma}
\end{gathered}
$$

where,

$$
\begin{array}{lll}
\phi & = & \text { fully guarded value } \\
\sigma & = & \text { ST value. }
\end{array}
$$

Solving for the fully guarded value, $\phi, \square$ given the measured ST, $\sigma$, results in equation 2 :

\footnotetext{
${ }^{3}$ Envelope Perimeter is used to describe the sum of all the lengths of the edges unit.
} 


$$
\begin{gathered}
\phi=\left(\alpha_{0}+\alpha_{1,1} X_{1,1}+\alpha_{1,2} X_{1,2}+\alpha_{1,3} X_{1,3}+\alpha_{2,1} X_{2,1}+\alpha_{2,2} X_{2,2}\right. \\
\left.+\alpha_{3} X_{3}+\alpha_{4} X_{4}+\alpha_{5} X_{5}+\alpha_{6} X_{6}\right) \times \sigma
\end{gathered}
$$

Equation (2) expressed in a simpler form becomes equation (3)

$$
\phi=\rho_{f s} \times \sigma
$$

The signs of the coefficients describe whether $\rho_{f s}$ increases or decreases with a unit change in variables. For example, a unit increase in shared surface area (X4) will decrease the $\rho_{f s}$ since its coefficient is negative. This is illustrated in Figure 4.

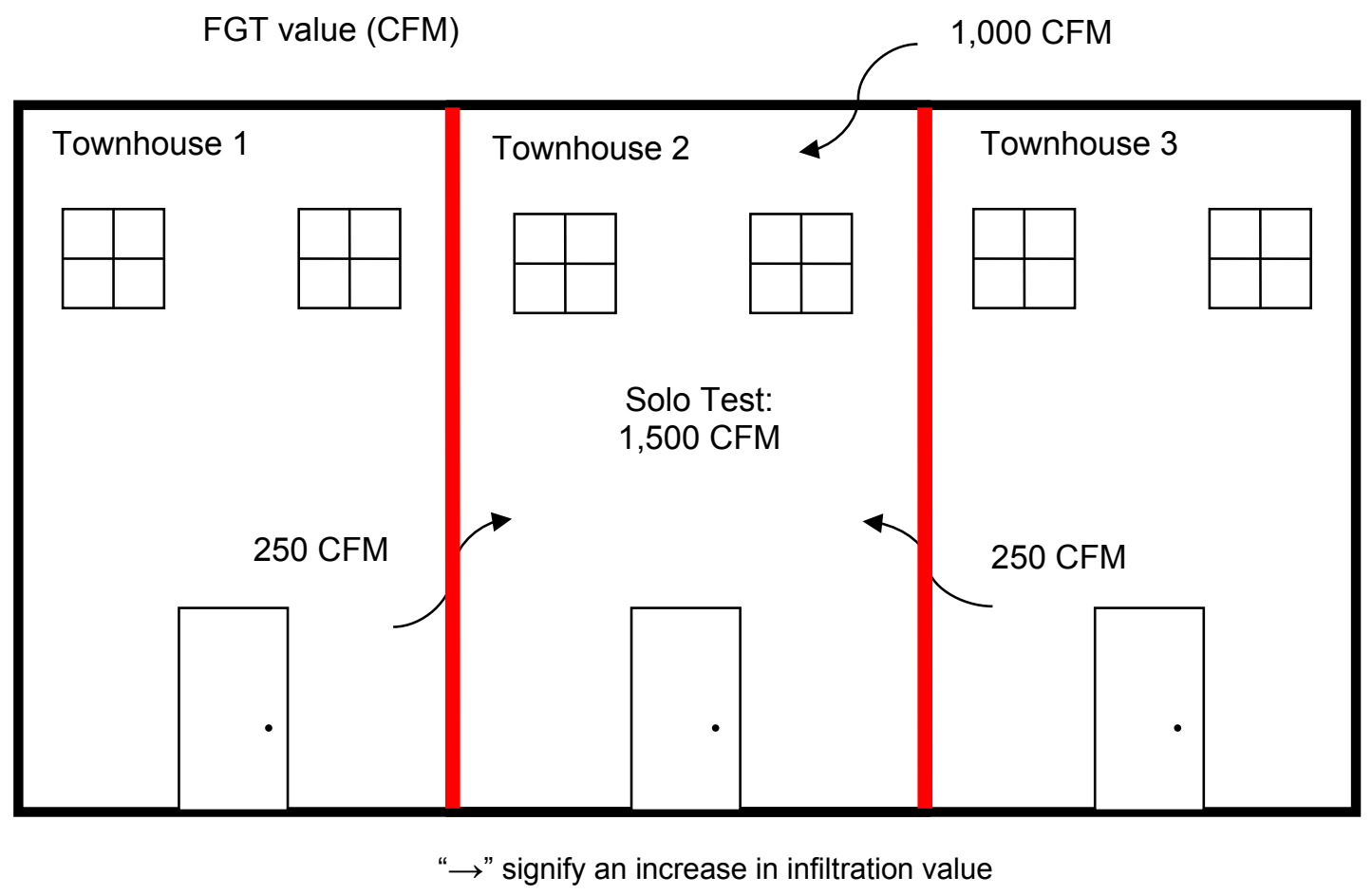

Figure 4. Effects of shared surface area on $\rho_{f s}$

Considering the middle unit (townhouse 2), if all other variables are held constant, an increase in shared surface area (shown in red lines) would result in an increase in the air leakage from connecting units. If the leakage from outside (1000 CFM) is equal to the fully guarded value then the ST before an increase in shared surface area is:

$$
\sigma=1000+(250+250)=1500
$$

Thus ratio $\left(\rho_{f s}\right)$ of fully guarded $(\phi)$ to ST $(\sigma)$ door value is:

$$
\rho_{f s}=\frac{\phi}{\sigma}=\frac{1000}{1500}=0.67
$$


After increasing shared surface area $\left(X_{1}\right)$, if the air leakage from adjoining units increased to 300 CFM then:

$$
\rho_{f s}=\frac{\phi}{\sigma}=\frac{1000}{1000+(300+300)}=\frac{1000}{1600}=0.63 .
$$

This illustration shows that based on the data, the greater the shared surface area, the lower the guarded to ST ratio. This method of verification might not be true for all variables, as the effects of other variables cannot always be held constant from one unit or building to another.

As mentioned above, dummy variables were created using a coding scheme, which chooses a level in the categorical variable as a reference (base) point. The reference variable for climate zone $\left(X_{1}\right)$ is climate zone 3a (ClimateZone_3a) and that of ductwork loaction $\left(X_{2}\right)$ is no ductwork (DuctworkLocation_None). The value of the base point is the value when all other levels in a categorical variable are set to zero and the intercept of the model is the sum of the base values from each categorical variable. For example, in the model described above, the $\rho_{f s}$ for a unit in climate zone 3 with no ducts will be at least $\alpha_{0}$ plus the effects of the other numerical predictors as shown below:

$$
\rho_{f s}=\alpha_{0}+\alpha_{1,1} \times 0+\alpha_{1,2} \times 0+\alpha_{1,3} \times 0+\alpha_{2,1} \times 0+\alpha_{2,2} \times 0+\alpha_{3} X_{3}+\alpha_{4} X_{4}+\alpha_{5} X_{5}+\alpha_{6} X_{6} \text {. }
$$

Solving the equation resolves into:

$\rho_{f s}=\alpha_{0}+\alpha_{3} X_{3}+\alpha_{4} X_{4}+\alpha_{5} X_{5}+\alpha_{6} X_{6}$

An ANOCOVA was performed to further assess the significance of the predictor variables. ANOCOVA is the analysis of the covariance of predictor variables to determine if there are significant differences between each level of categorical predictors as well as numerical predictors. Table 5 shows the results of the ANOCOVA where the p-value is the probability that the variables' coefficient is zero. The p-values for all predictor variables are less than 0.05 , indicating that the coefficients of the predictor variables are significant to the model at a $95 \%$ confidence interval. This confirms the significance of the selected variables from the stepwise regression.

\begin{tabular}{|c|c|c|c|}
\hline Source & & Number of Levels & p-Value \\
\hline ClimateZone & $X_{1}$ & 3 & $6.20 \mathrm{E}-09$ \\
\hline DuctworkLocation & $X_{2}$ & 2 & $2.12 \mathrm{E}-16$ \\
\hline DoorArea $\left(\mathbf{f t}^{2}\right)$ & $X_{3}$ & 1 & $3.61 \mathrm{E}-07$ \\
\hline SharedSurfaceArea $\left(\mathrm{ft}^{2}\right)$ & $X_{4}$ & 1 & $1.69 \mathrm{E}-06$ \\
\hline EnvelopePerimeter (ft) & $X_{5}$ & 1 & $3.03 \mathrm{E}-06$ \\
\hline Age (years) & $X_{6}$ & 1 & $2.62 \mathrm{E}-08$ \\
\hline
\end{tabular}

Table 5. ANOCOVA Variables for Model 
Figure 5 shows the relationship between the adjusted response, $\rho_{f s}$ (labeled as adjusted $\mathrm{R}_{f s}$ ) and the adjusted predictor values. The adjusted predictor values represent the incremental effect on the response of a specified variable by removing the effects of all other variables. The slope of each variable's line is equal to its coefficient in the model with the exception of categorical variables, climate zone (X1) and ductwork location (X2), where the slope represents the combined incremental effect of all levels in the variable. Once a horizontal line cannot be drawn within the confines of the $95 \%$ confidence dotted line margins, the variables are said to be significant. All graphs in Figure 5, confirm to this rule, thus backing the significance of the variables in the model. Graph $(5 \mathrm{~g})$, shows the graph of the predicted against measured $\rho_{f s}$. The linear trend of the points along the solid red line also confirms the validity of the model.

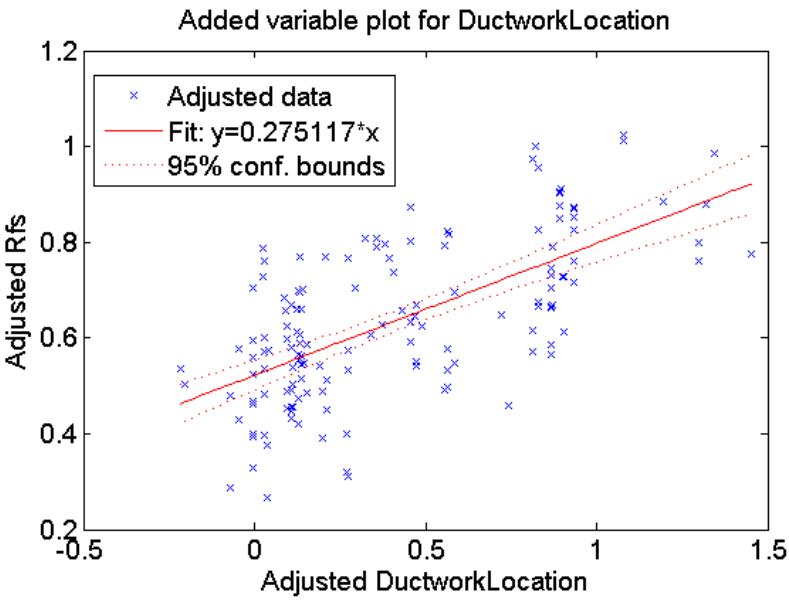

(a)

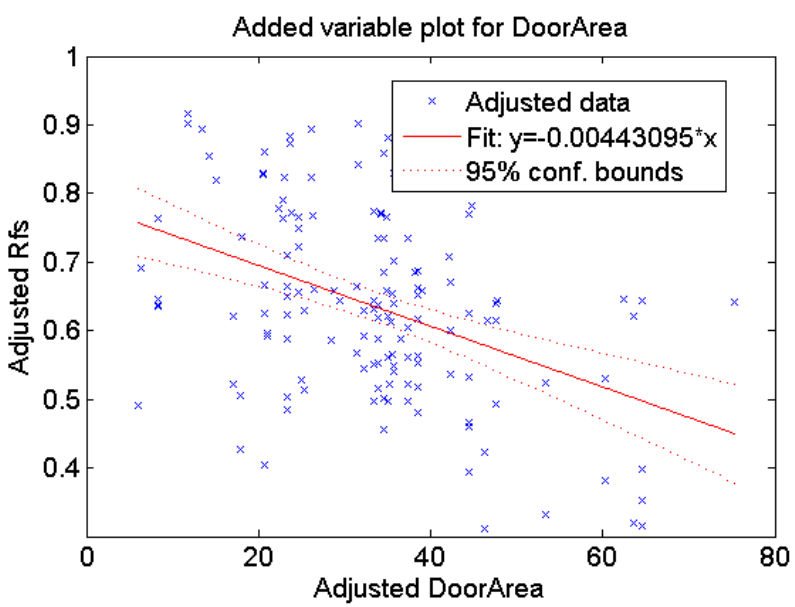

(c)

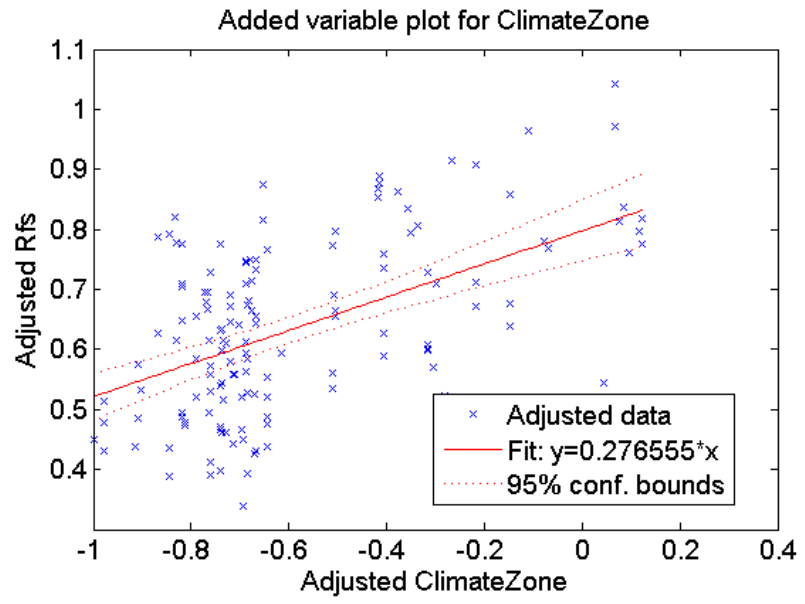

(b)

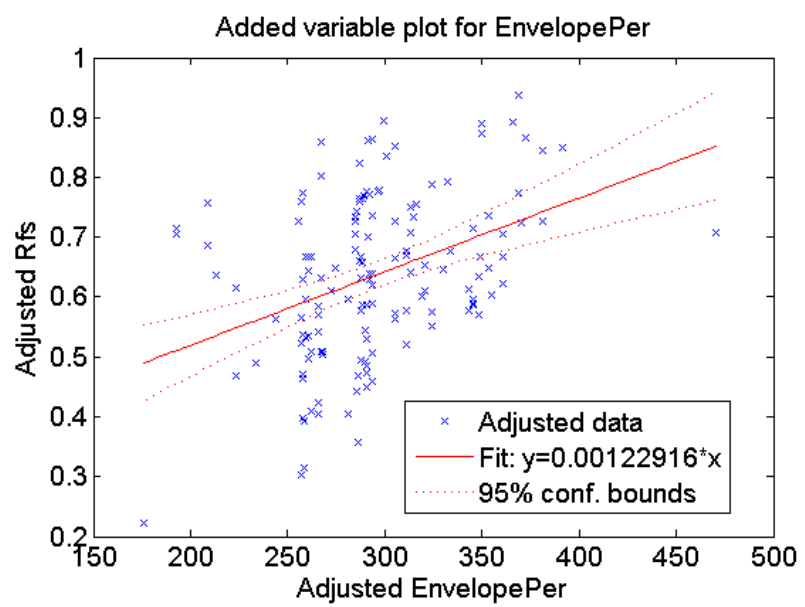

(d) 


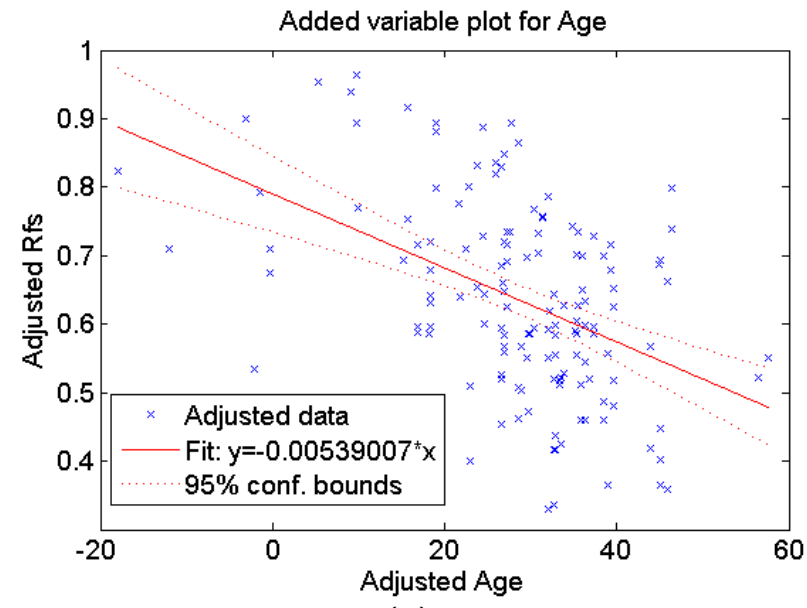

(e)

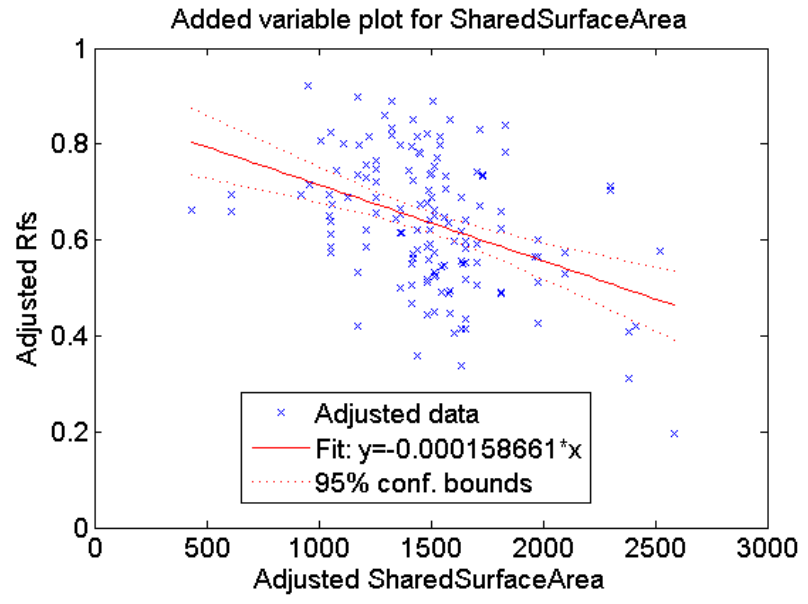

(f)

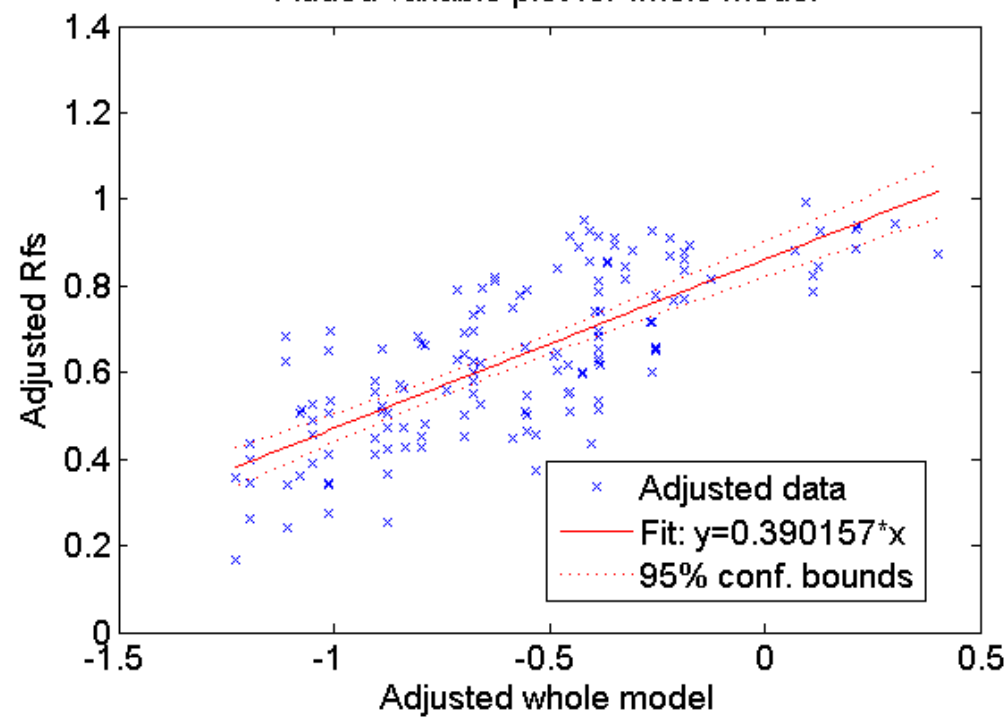

(g)

Figure 5. Adjusted plots for predictors in model

The model had an adjusted $\mathrm{R}^{2}$ of 0.53 , which means that $53 \%$ of the variation in the data can be described by the model. Adjusted $\mathrm{R}^{2}$ comes from a similar concept of the $\mathrm{R}^{2}$ value, however it adjusts for the degrees of freedom in the model. The value of $\mathrm{R}^{2}$ ranges from 0 to 1 and the closer the value to 1 , the more accurate the model. A larger adjusted $\mathrm{R}^{2}$ value implies that a greater proportion of the variance in the data can be explained by the model. Adjusted $\mathrm{R}^{2}$ is a more accurate measure of how well a model explains the variation in a data set, since larger number predictors could give a deceivingly high $\mathrm{R}^{2}$ value. An adjusted $\mathrm{R}^{2}$ of 0.53 for a model created from measured values that have a wide range of uncertainty is statically justifiable but certainly a higher adjusted $\mathrm{R}^{2}$ is preferred. The root mean square area of the model (RMSE) was 0.13. It measures how far the predicted values are from measured values. An RMSE value of 0.13 is acceptable since $\rho_{f s}$ ranges from 0 to 1 . 


\subsection{Applying Results}

As indicated above, the model was trained with $60 \%$ of the data randomly selected and the resultant model shown in equation (2) was tested with the remaining $40 \%$ of the data. The predicted fully guarded value was calculated along with its accuracy at a $95 \%$ confidence interval. The model was applied to $40 \%$ of the remaining data and the RMSE was also 0.13 . Since the ultimate goal of the model is to predict a fully guarded value, an RMSE of 0.13 in terms of $\rho_{f s}$ was translated to an RMSE of 98 CFM in units of fully guarded values. There are several ways to measure the accuracy of a predictive model. For this report the mean absolute percentage error was chosen and shown equation (1). This measures how far a prediction is from the measured guarded blower door values and expressed as a percentage of the measured value.

$$
\delta=100 \times \frac{1}{n} \sum_{t=1}^{n}\left|\frac{M_{t}-P_{t}}{M_{t}}\right|
$$

where:

$\begin{array}{lll}\delta & = & \text { prediction accuracy }(\%) \\ \mathrm{n} & = & \text { number of observations } \\ \mathrm{M} & = & \text { measured unguarded blower door values } \\ \mathrm{P} & = & \text { predicted blower door values }\end{array}$

The percentage accuracy was calculated to be $19.6 \%$. Figure 6 shows the results when applying the model to unit data that did not go into training the model. The blue dots represent the predicted and measured FGT value for each unit. The dots lying close to the red dash line are indicative of the model's accuracy that was calculated to be $19.6 \%$.
Accuracy of Prediction The RMSE area of the model was 0.13 . It measures how far the predicted values are from measured values. Since the ultimate goal of the model is to predict a fully guarded value, the RMSE of 0.13 was used to calculate a coefficient of variation of the RMSE of $19 \%$ for the fully guarded values.

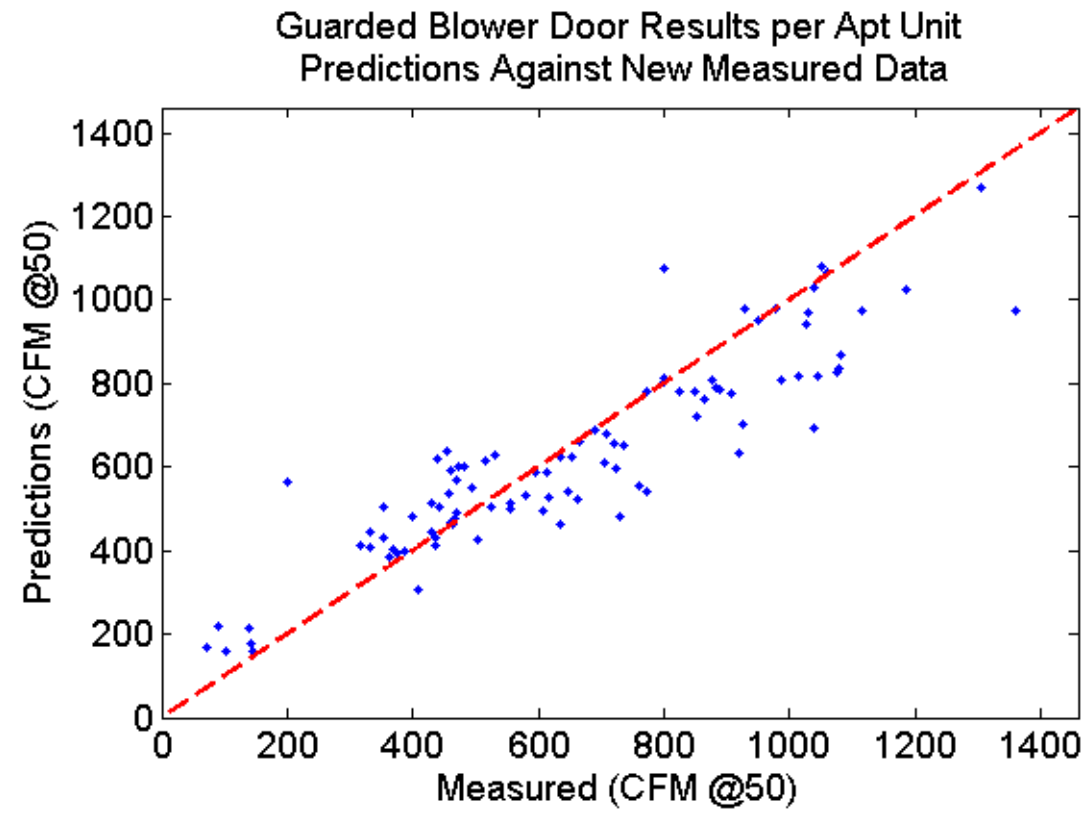

Figure 6. Predicted FGT value against ST value using the model 
The following is an example of how the model can be applied in the field. Table 6 shows data for the variables needed by the model for prediction.

Table 6. Test Data

\begin{tabular}{|c|c|c|c|c|c|c|c|}
\hline $\begin{array}{l}\text { Unit } \\
\text { ID }\end{array}$ & $\begin{array}{c}\text { Climate } \\
\text { Zone } \\
(\mathbf{X} 1, \mathbf{i}) *\end{array}$ & $\begin{array}{l}\text { Ductwork } \\
\text { Location } \\
(\mathrm{X} 2, \mathbf{j}) * *\end{array}$ & $\begin{array}{c}\text { Door } \\
\text { Area, } \mathbf{f t}^{2} \\
(\mathrm{X} 3)\end{array}$ & $\begin{array}{c}\text { Shared } \\
\text { Surface } \\
\text { Area, ft }^{2} \\
\text { (X4) }\end{array}$ & $\begin{array}{c}\text { Envelope } \\
\text { Perimeter, } \\
\text { ft } \\
\text { (X5) }\end{array}$ & $\begin{array}{c}\text { Age, } \\
\text { years } \\
\text { (X6) }\end{array}$ & $\begin{array}{c}\text { ST } \\
\text { Value, } \\
\operatorname{cfm}(\sigma)\end{array}$ \\
\hline 1 & 4a $\quad X_{1,1}$ & $\begin{array}{c}\text { Conditioned } \\
\text { space }\end{array} \quad X_{2,1}$ & 18 & 1,052 & 396 & 43 & 1,821 \\
\hline
\end{tabular}

$* \mathrm{i}=$ number of levels in climate zone

$* * \mathrm{j}=$ number of levels in ductwork location

Any data that use this model to predict leakage to outside must have information on the six predictors shown in Table 6. As indicated, Unit 1 is located in climate zone 4a, has its ductwork in conditioned space, a surface area of $1052 \mathrm{ft}^{2}$, envelope perimeter of $369 \mathrm{ft}$, and is 43 years old. Table 7 shows how this information is used by the model and how $\rho_{f s}$ is calculated.

Table 7. Example of Applying Model

\begin{tabular}{|c|c|c|c|c|c|c|}
\hline \multirow{2}{*}{\multicolumn{2}{|c|}{ Predictor Variables $(\mathrm{X})$}} & \multirow{2}{*}{\multicolumn{2}{|c|}{ Coefficients $(\alpha)$}} & \multicolumn{3}{|c|}{ Unit 1} \\
\hline & & & & \multirow{2}{*}{$\begin{array}{r}\text { Unit } \\
\text { Info. } \\
1\end{array}$} & \multicolumn{2}{|c|}{ Calculations } \\
\hline$X_{0}$ & Intercept & $\alpha_{0}$ & $8.61 \mathrm{E}-01$ & & $1 \times 8.61 \mathrm{E}-01$ & 0.861 \\
\hline$X_{1,1}$ & ClimateZone $4 \mathrm{a}$ & $\alpha_{1,1}$ & $-2.50 \mathrm{E}-01$ & 1 & $1 \times-2.50 \mathrm{E}-01$ & -0.250 \\
\hline$X_{1,2}$ & ClimateZone_5a & $\alpha_{1,2}$ & $-4.23 \mathrm{E}-02$ & 0 & $0 \times-4.23 \mathrm{E}-02$ & 0.000 \\
\hline$X_{1,3}$ & ClimateZonw_6a & $\alpha_{1,3}$ & $-1.10 \mathrm{E}-01$ & 0 & $0 \times-1.10 \mathrm{E}-01$ & 0.000 \\
\hline$X_{2,1}$ & $\begin{array}{l}\text { DuctworkLocation_- } \\
\text { conditioned space }\end{array}$ & $\alpha_{2,1}$ & $5.11 \mathrm{E}-02$ & 1 & $1 \times 5.11 \mathrm{E}-02$ & 0.051 \\
\hline $\boldsymbol{X}_{2,2}$ & $\begin{array}{l}\text { DuctworkLocation } \\
\text { unconditioned space }\end{array}$ & $\alpha_{2,2}$ & $2.70 \mathrm{E}-01$ & 0 & $0 \times 2.70 \mathrm{E}-01$ & 0.000 \\
\hline$X_{3}$ & DoorArea $\left(\mathrm{ft}^{2}\right)$ & $\alpha_{3}$ & $-4.43 \mathrm{E}-03$ & 18 & $18 \times-4.43 \mathrm{E}-03$ & -0.080 \\
\hline$X_{4}$ & $\begin{array}{l}\text { SharedSurfaceArea } \\
\left(\mathrm{ft}^{2}\right)\end{array}$ & $\alpha_{4}$ & $-1.59 \mathrm{E}-04$ & 1,052 & $\begin{array}{c}1,052 \times-1.59 \mathrm{E}- \\
04\end{array}$ & -0.167 \\
\hline$X_{5}$ & $\begin{array}{l}\text { EnvelopePerimeter } \\
\text { (ft) }\end{array}$ & $\alpha_{5}$ & $1.23 \mathrm{E}-03$ & 396 & $369 \times 1.23 \mathrm{E}-03$ & 0.454 \\
\hline$X_{6}$ & Age (years) & $\alpha_{6}$ & $-5.39 \mathrm{E}-03$ & 43 & $43 \times-5.39 \mathrm{E}-03$ & -0.232 \\
\hline$\rho_{f s}$ & Ratio of $\phi$ to $\sigma$ & & & & & 0.637 \\
\hline
\end{tabular}

Given that the ST value for unit 1 is 842 CFM. Equation (3) is then used to calculate the predicted $\phi$ value:

$$
\phi=\rho_{f s} \times \sigma=0.637 \times 842=536 C F M
$$




\section{Discussion}

\subsection{Accuracy}

To further assess the model's accuracy of $\pm 19.6 \%$, the model was applied to a new dataset and the results are discussed below. The new dataset was composed of 14 units from two apartmentstyle building complexes located in International Energy Conservation Code climate zone 5A. Each unit had both guarded and unguarded blower door results pre and post retrofit. One building also had blower door testing performed during the retrofit process.

Figure 7 shows how well the predicted guarded values match up against the measured guarded values from the new dataset. Units with measured guarded values around $400 \mathrm{CFM}_{50}$ are closer to the red line which represents a perfect model. This is because the training data had more guarded values within the $250-450 \mathrm{CFM}_{50}$ range as shown in Figure 8, as such the model predicts best within this range. Nonetheless, the accuracy of the prediction on these new data was $\pm 13.2 \%$, which is even better than the $\pm 19.6 \%$ obtained above from the test data.

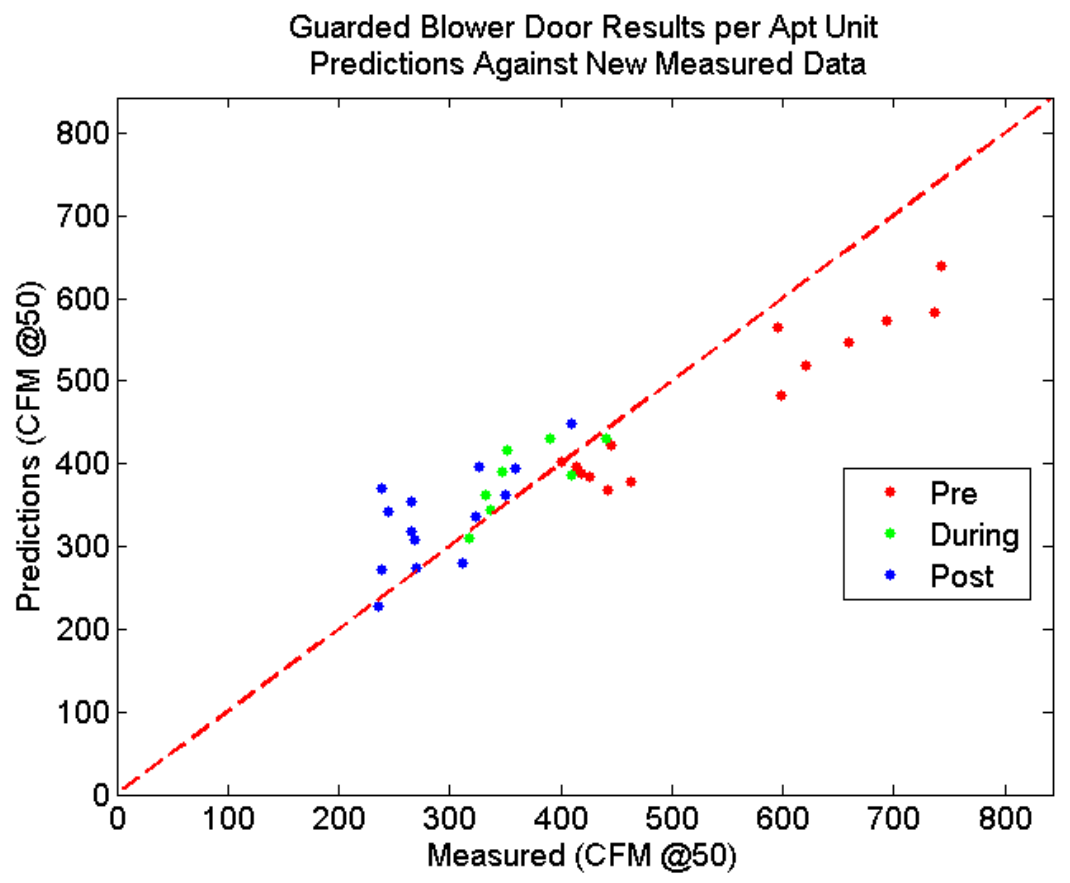

Figure 7. Model results on new data 


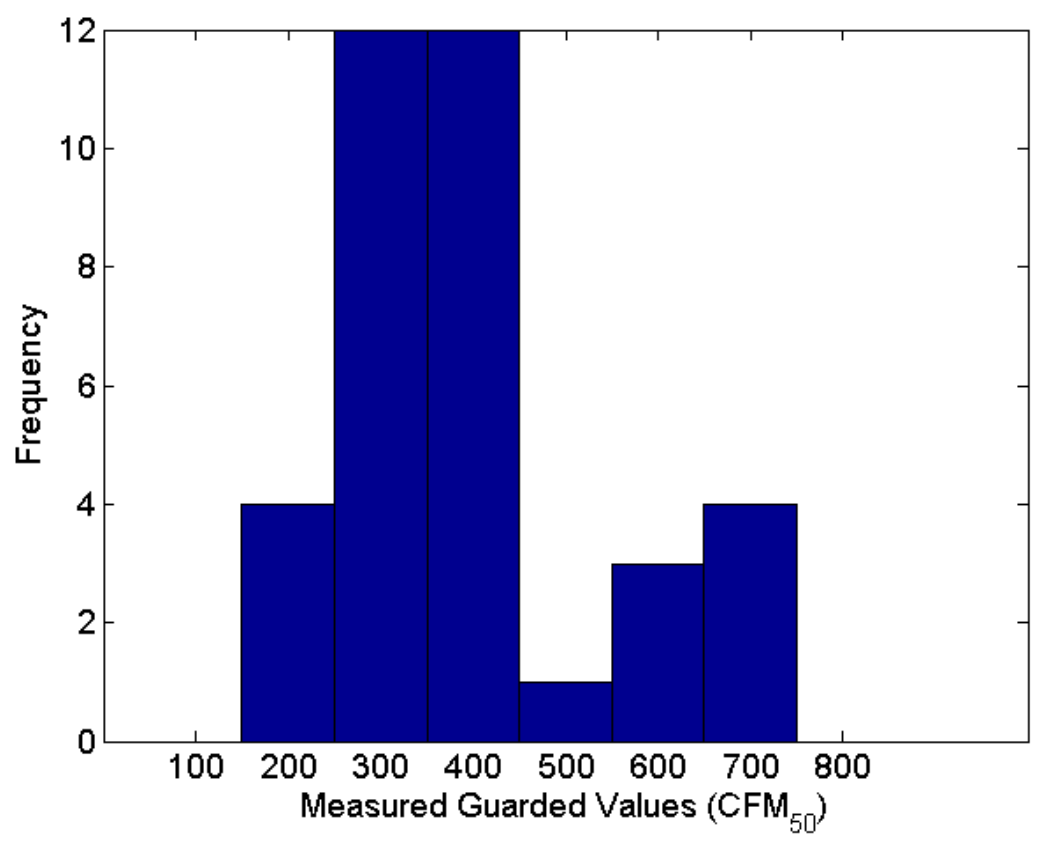

Figure 8. Distribution of measured guarded values

It can also be seen in Figure 8 that, with the exception of a few points, most of the pre-retrofit guarded values are underpredicted. A case could be made for resolving this issue by adding a variable for construction type that is, whether new, pre- or post-retrofit construction. However, since the training dataset was relatively small adding more variables would have led to overfitting, and reduce the predicting power of the model. According to the 2009 Residential Energy Consumption Survey, there are about 6.7 million single-family attached and low-rise multifamily units in the United States. Thus, 384 apartment units are needed to create a model for a population of 100 million with confidence level of $95 \%$ and margin of error of 5\% (The Research Advisors 2006). The model was created and trained with $60 \%$ of 236 units - short of the 384 units mark.

One of the biggest stumbling blocks in creating a more robust model is the lack of available data. Due to the extensive amount of time and expense that goes into conducting an FGT in addition to an ST, very few data are available. Raters and researchers throughout the country were contacted. Moreover, some units that had both tests done were lacking other information relating to the units' specification.

\subsection{Impact}

To assess the impact of using a predicted envelope leakage value rather than a measured total leakage value in a simulation model, an EA-QUIP model was used from a retrofit project in Philadelphia. Developed in the 1980s, EA-QUIP is still a commonly used and the U.S.

Department of Energy approved energy modeling software for multifamily buildings. In this case, EA-QUIP results were used to obtain project financing from the Pennsylvania Housing Finance Agency. EA-QUIP determines economically optimal mixes of energy-saving measures for a given building and within a chosen budget, for which it uses retrofit and cost libraries. 
For this exercise, two ACH values were calculated; one from the CFM50 value from a measured ST and the other from a predicted fully guarded value using the model in equation (2). The Nfactor used to convert CFM50 values to $\mathrm{ACH}$ was 11.7. $\mathrm{N}$ factor is a numerical factor reflecting wind speed, shielding of the building, the height of the building as well as what climate zone the building is in. $\mathrm{N}$ factors range from $11.7-22.2$.

Table 8. EA-QUIP Results

\begin{tabular}{c|c|c}
\hline Blower Test & ST & Fully Guarded (Predicted) \\
\hline ACH & 0.36 & 0.16 \\
Original Building (MMBtu/yr) & 737 & 473 \\
Retrofitted Building (MMBtu/yr) & 716 & 463 \\
Energy Savings & $2.84 \%$ & $1.95 \%$ \\
Savings to Investment Ratio (SIR) & 1.88 & 0.75 \\
\hline
\end{tabular}

The results shown in Table 8 are based on selected air-sealing retrofits measures. As expected it is seen that when the $\mathrm{ACH}$ of the building is reduced from 0.36 to 0.16 , the predicted heating energy use is also reduced along with the percentage predicted energy savings and SIR. The higher predicted energy savings and SIR values from the ST value assumes that the total leakage is all to the outside. Thus, using the more appropriate predicted envelope leakage changes the SIR for air-sealing measures from above 1.0 to below 1.0 . 


\section{Conclusion}

This research sought to answer the following questions:

- Can an empirical model based on a single blower door test and easily accessible data be developed for predicting thermal envelope leakage in multifamily buildings across the United States?

- Can this model be applied with reasonable accuracy across various types of buildings and across different climate regions?

Using data for 236 dwelling units from 17 multifamily buildings across four different climate zones a stepwise regression analysis was performed and six variables were selected as significant predictors. They are climate zone, ductwork location, door area, shared surface area, envelope perimeter and age. The empirical model is:

$$
\phi=\left(0.8610+\alpha_{1}+\alpha_{2}-0.0044 X_{3}-0.0002 X_{4}+0.0012 X_{5}+0.0054 X_{6}\right) \times \sigma
$$

where:

$$
\begin{aligned}
& \alpha_{1}\left\{\begin{array}{lr}
\text { ClimateZone_4a } & -0.2500 \\
\text { ClimateZone_5a } & -0.0423 \\
\text { ClimateZone_6a } & -0.1100
\end{array}\right. \\
& \alpha_{2} \begin{cases}\text { DuctworkLocation_conditioned space } & 0.0511 \\
\text { DuctworkLocation_unconditioned space } & 0.2700\end{cases} \\
& X_{3} \quad=\text { DoorArea }\left(\mathrm{ft}^{2}\right) \\
& X_{4}=\text { SharedSurfaceArea }\left(\mathrm{ft}^{2}\right) \\
& X_{5} \quad=\text { EnvelopePerimeter }^{4}(\mathrm{ft}) \\
& X_{6} \quad=\text { Age (years) } \\
& \phi \quad=\text { predicted fully guarded value } \\
& \sigma=\text { measured solo test value }
\end{aligned}
$$

The $\mathrm{R}^{2}$ value of the model is 0.53 with an RMSE of 0.13 . When tested against data that were not used to develop the model, prediction accuracy was within $19.6 \%$. Thus, the model is relatively strong and, with only six predictors, it is relatively easy to apply.

\footnotetext{
${ }^{4}$ Envelope perimeter is used to describe the sum of all the lengths of the edges of the unit, common, and exterior surfaces..
} 


\section{References}

Chatterjee, S.; Price, B. (1938). Regression Analysis by Example. 2nd Edition. New York: John Wiley \& Sons, Inc.

DeGroot, M.H.; Schervish, M.J. (1931-1989). Probability and Statistics, 4th Edition.

Genge, C. (2007). "Measuring Leakage in High-Rise Buildings.” Home Energy Magazine, September/October 2007.

HMG (2012). Study of Multi-Family Air Leakage Testing Strategies, Final Report, HMG Project Number 1014. Heschong Mahone Group, Inc., August 10, 2012.

Hult, E.L.; Dickerhoff, D.J.; Price, P.N. (2012). Measurement Methods to Determine Air Leakage Between Adjacent Zones. LBNL-5887E. Lawrence Berkeley National Laboratory, September 2012.

Hynek, D. (2011). "Blower Door Testing in Multifamily Buildings.” Home Energy Magazine, September/October 2011.

Lewis-Beck M.S. (1978). "Stepwise Regression: A Caution.” Political Methodology 5(2), 213240. Accessed July 5, 2013.

Lukachko A, Grin A, and D. Bergey. 2013. Hybrid Wall Evaluation for Ten New Construction Homes in Wyandotte, Michigan. DOE/GO-102013-3634. National Renewable Energy Laboratory.

MATLAB (2010). Version 8.0.0.783. Natick, MA: The MathWorks Inc.

MathWorks. (2013). Statistics Toolbox: User’s Guide (R2013a).

Massey, F.J. (1951). "The Kolmogorov-Smirnov Test for Goodness of Fit." Journal of the American Statistical Association 46(253): 68-78.

NREL (2001a). Weatherize your home-Caulk and Weather Strip. DOE/GO-102001-1172. FS203. Golden, CO: National Renewable Energy Laboratory.

NREL (2001b). Saving Energy with Electric Resistance Heating. DOE/GO-102001-1172 FS203. Golden, CO: National Renewable Energy Laboratory.

NYSERDA (1995). "Simplified Multizone Blower Door Techniques for Multifamily Buildings." New York State Energy Research and Development Authority, NYSERDA Report 95-16.

Roecker, B.E. (1991). "Prediction Error and Its Estimation for Subset-Selected Models." Technometrics 33 (4): 459-468.

Sheltair (1987). "Methods for Airtightness Testing of Multi-unit R-2000 Housing." Sheltair Scientific Ltd. 
Sherman, M. 2007. Air Leakage of US Homes: Model Prediction. American Society of Heating Refrigeration and Air Conditioning Engineers, Inc.

The Research Advisors (2006). “Sample Size Table.” Accessed October 09 2013: http:/www.research-advisors.com/tools/SampleSize.htm.

UCLA (2013). Coding for Categorical Variables in Regression Models. UCLA: Statistical Consulting Group. 
